\title{
Theoretical Basis of Situational Teaching Method and Its Application in Chinese Teaching
}

\author{
Haibin Yu \\ School of Education and Sports, Bohai University, Jinzhou, 121013, China \\ yu_hb@163.com
}

Keywords: situational teaching method; theoretical basis; Chinese teaching; application ways; matters needing attention

\begin{abstract}
Situational teaching can help students to better understand and apply Chinese knowledge. Constructivism, based on the situational teaching, the theory of situational learning, the principle of "Socratic Method" and the intuitionistic principle of cognition; this paper puts forward the ways of creating situation in Chinese teaching, including "reading experience situation, language description situation, music rendering situation, image representation situation, the physical demonstration situation and the life show situation" etc; point out notes in the use of situational teaching method in Chinese teaching, including "create a specific aim, create an equal relationship between teachers and students, the development of situation effect, pay attention to the authenticity of the situation, ensure a good atmosphere for exchange and cooperation, pay attention to the ability of students to explore" and so on.
\end{abstract}

\section{Introduction}

Situational teaching method refers to the basic principles of pedagogy and psychology in the process of teaching, and the purpose of teachers is to introduce or create a certain emotional meaning, imaging as the main body of the vivid specific scene, causing students a certain attitude experience, stimulating students to participate motive, enable students to make the knowledge and daily life experience link to the old knowledge and new knowledge integration, so as to help students understand the teaching materials, and teaching methods make the psychological function of students can be developed. The center of situational teaching is to inspire students' emotions. Situational teaching method has three characteristics: first, specificity, teachers according to the specific content of teaching, combined with specific life scenes, the use of classroom stage for students to create a specific, imagic and intuitive learning environment; second, visualization, the use of information technology, audio equipment, pictures and other external method to create classroom scenarios, so that students are immersive, and truly feel the existence of the scene, through a number of dimensions to observe and understand the learning object; third, pleasure, interest is the best teacher, through the creation of the scene, students can feel the characteristics of learning objects, resulting in continuous study interest of the object.

Language as a basic subject, for cultivating students' ability to learn and improving the humane accomplishment is a very important role. Chinese teaching belongs to humanistic category, and Chinese knowledge teaching is more dependent on situational application. At present, the Chinese teaching is still difficult to get rid of the shackles of exam-oriented education, although the education sector has been advocating to get rid of exam-oriented education, highlighting the overall quality of students training, but the implementation of language teaching in the classroom, spoon-fed education model is still the main way of knowledge teaching [1] The Chinese teaching plays an important role in shaping the overall quality of students. Chinese has many levels of knowledge, both modern knowledge and ancient allusions. It has both oriental national characteristics and western culture. Situational teaching can help students to understand and use better the language knowledge, expanding the understanding of space and improve the training opportunities for the cultivation of students' overall quality of great value. 


\section{Theoretical Basis of Situational Teaching Method}

The research and application of situational teaching method is based on the following theoretical basis:

(1) Constructivism theory. Constructivism agrees that knowledge is not obtained by the teacher's teaching, but the learners' acquire in a certain situation, that is, in the background of social culture, with the help of others, using the necessary learning materials, through the meaning construction method. Due to learning is in a certain situation, with the help of others, that is, through the interpersonal collaboration activities to achieve the meaning of the construction process, therefore, constructivism learning theory considers that "situation", "collaboration", "conversation" and "meaning construction" which is the four elements in the learning environment . The situation in the learning environment must be conducive to the meaning construction of students. In the constructivism learning environment, the teaching design should not only consider the teaching goal analysis, but also consider situation creation problem which is beneficial to the students' constructivism, and regard the situation creation as one of the most important teaching design. Through the creation of situation according to the teaching content and tips between the old and new links between the knowledge to help students to build the meaning of the current knowledge.

(2) Situational learning theory. Situational learning theory holds that learning is not only the psychological process of individual meaning construction, but also a social, practical, participatory process with differentiated resources. The meaning of knowledge with the learners' own consciousness and role are generated in the interaction between learners and learners. Therefore, the creation of learning situation commits itself to the learner's identity and role consciousness, complete life experience, and cognitive tasks to return to the real and confluent state, to solve the traditional school learning problem without ego and situation. The Situational learning emphasizes two principles of learning: first, establish knowledge in a real practical applicational situation, combine the learning and using, so that let the learners like experts to think and practice; second, through social interaction and collaboration to learn.

(3) "Socratic Method" theory [2]. Ancient Greek famous philosophers put forward the famous "Socratic Method", he said: "I do not teach others by knowledge, but do their own production of knowledge." He divides teaching into three steps: irony, midwifery, induction and definition, in the satirical period is mainly to set problems. The specific process of teaching is: raise a question, students answer, teachers ask questions, students fall into contradiction. In the midwifery period is mainly to inspire and guide students, so that students through their own thinking to draw conclusions. In the induction period, make students gradually grasp the specific definition and concept. At the beginning of teaching, that is to create a problem situation, learning from thinking, thinking from the questioning, the creation of the problem situation, improve the learning interest, stimulate the learning motivation, guide students to further study and explore, and then improve learning efficiency.

(4) The intuitive theory of cognition [3]. From the methodology, situational teaching is the use of the theory of reflection, according to the objective existence effects on the student's subjective consciousness, and consciousness is a reflection of the objective existence. The situation created by situational teaching, because the environment which is created by the people's consciousness and is conducive to the external environment development of students. This optimized objective situation, under the control of the teacher's language, puts students in the specific situation, Not only affect the students 'cognitive psychology, but also promote students' emotional activities to participate in learning, which led the students motivate themselves. Situational teaching method, enable students an immersive experience, through show students a distinctive image, so that students gain abstract rational insight from the image of perception, motivate students' learning mood and learning interest, so that learning activities become students' active and conscious activities. 


\section{Ways of Creating Situations in Chinese Teaching}

Aiming at the characteristics of Chinese curriculum, the following ways can be used to create the situation of the teaching process:

(1) Reading experience situation. Reading teaching is a dialogue process between students, teachers and texts. Reading is student's individual behavior, teachers should cherish the unique feelings of students, experience and understanding. Chinese reading situation is created by the teacher according to the content of the text, which can inspire students to explore the desire of reading and have the objective environment of reading content. Teachers should fully respect the students, encourage students through a unique perspective to understand and unscramble the text. Emotional experience through the facial expressions, demeanor, action and language, etc., resonantly. Read aloud to pour out our own voices, express the characters of the text thoughts, so that students in reading can really experience the joy of spiritual labor.

(2) Language description situation. Teachers should fully excavate the inherent charm of Chinese teaching materials, design vivid teaching situation, arouse students curiosity. Students are driven by curiosity and have a strong interest in exploring unknown knowledge. The use of action, expression and other body language, and actively use a variety of vivid expression, the imagic language, the presentation action to describe things, and strive to be realistic, to help students understand. When the situation appear, teachers with language description, which plays a guiding role in the cognitive activities for students. Language description improve the perceived effect, the situation will be more vivid, and with an emotional role in the students' senses.

(3) Performance experience situation. The performance of the situation is through the role of the play to achieve, especially in primary school Chinese teaching is very applicable. Primary school Chinese teaching materials like fairy tale, fables and stories are so good for students to perform. Those wolves, little goats, big cock and pony, students are eager to perform. The role of teaching materials vividly show in front of everyone. Students become enthusiastic actors or audience into the situation of teaching materials. This vivid form, let students particularly excited, both students can hear, also see, with rich drama, and students welcome and impressive is an inevitable result.

(4) Music rendering situation. Language and music have a tightly bond, letting beautiful melody into Chinese classroom, you can give students the feeling of beauty, training students' noble sentiment. In the teaching of Chinese, the combination of music and writing, the use of music rendering teaching situation, music to stimulate students' emotions, the perfect combination of language and music, stimulate students to learn the Chinese with interest, to achieve good teaching results [4] The specific methods include: use music to build the situation for a new lesson, use songs to help understand the main idea of the text, use lyrics to help students remember the text content, through read with music to make the students appreciate the beautiful meaning of the article. Teachers, in the introduction or summary words with music, resulting in emotional resonance, so that Chinese class is more aesthetic.

(5) Image reproduction situation. With picture to reproduce the text situation, the text can be specification and visualization. The color and content of the painting are easy for students to accept and understand. In junior grade Chinese teaching materials, each text has illustrations accompanied, using situational teaching and dynamic picture to attract students learning attention and to stimulate students interest in learning. The development of information technology has changed the traditional teaching model, and educational information has brought profound changes in teaching methods and ways. By using the application of multimedia for Chinese classroom teaching, students can mobilize the enthusiasm for learning Chinese. The use of multimedia courseware let the students into the situation, enhance the theme of feelings, and mobilize the students' emotional participation.

(6) Physical demonstration situation. As the saying goes, "It is better to see for oneself rather than to hear for many times.", which is a way to understand the objective things. The use of the physical demonstration situation is arising from the law of cognition. Teachers base on the teaching objectives and teaching content, use physical visual demonstration, and the creation of specific 
context skills. The characteristics are intuitive, and students can feel, which is conducive to enrich the students' sensibility knowledge, triggering students with strong curiosity, helping students understand, verify the indirect knowledge, and format clear concept to develop students' ability to observe. The use of physical demonstration for situation, both help students understand the truth and enhance the real experience of students, which is conducive to stimulate students' learning interest, and saving class teaching time.

(7) Life show situation [5]. Design to meet the language material which is described in the life situation, through the perception of life to understand the difficulties and sense the work language, in order to restore language, and let students have a solid memory. The design needs to pay attention to the following questions: the situation must be close to the students' life, causing students to understand the phenomenon of life; situation needs to be similar with problems solving, on the contrary, it will guide students to think on the wrong road; the situation should not be too long, the content should not be too much, otherwise, it is easy to put students' attention into the life situation, deviate from the teaching theme; the language should be vivid, imagic, intuitive and concise, in the minds of students flashed a clear real life; highlight the situation of the seasonal and the characteristics of the time, so that the Chinese curriculum can always have the spirit of the times.

\section{Matters Needing Attention of Creating Situations in Chinese Teaching}

Situational teaching is an important way to improve students' Chinese learning level, but it also has two sides. If you use improperly, some problems will affect the teaching effect. Practical using should pay attention to the following points:

(1) Create situation with clear goal [6]. Chinese teaching use situational teaching method, according to the requirements of the new curriculum, and focus on the key and difficulties of the Chinese teaching materials to develop a reasonable teaching content. At the same time, students should also be aware of the problems encountered in the learning process to improve students' cognitive ability. In the Chinese teaching, students' cognitive and behavioral aspects may change, through the overall understanding of students to grasp, and in the process of solving problems to be targeted.

(2) Create equal relationship between teachers and students. Situational teaching should be carried out in an equal and harmonious atmosphere to ensure the harmonious relationship between teachers and students, and make students in the scene experience with a voluntary state to stimulate higher enthusiasm. Teachers try their best to provide services, based on the students need to fully understand, based on the individual characteristics need individual teaching, patiently listen to the views from students, pay attention to students' changes in students' emotions, care for students' life, treat students with equal attitude, create a happy learning environment for students.

(3) Attention to the development of situational role [7]. Teaching situational design not only for the existing level of students, but also enable students to extend the learning of knowledge, so that it can be extended and applied to the relevant knowledge, with the same side of the coverage. The design of the teaching situation is not only conducive to the comprehensive use of knowledge, is conducive to the consolidation and development of learning achievement, and is conducive to the development of individuality and expertise, is also conducive to students to learn from each other.

(4) Focus on the truth of situation. The more realistic the situation, the more reliable the knowledge of the subject construction, the easier it is to use it in the real situation. The character of the learning situation determines the validity of the learning methods and determines the likelihood that the knowledge will be reapplied in other situations. "Real situation" has the original real and artificial real points. The original real time and space often can not accommodate in the classroom , they need to construct artificial real. According to the original real to build artificial real, well-designed teaching situation, which is one of the important contents of teaching design, and is teachers' professional characteristics of creative labor [8].

(5) Ensure good atmosphere for exchanges and cooperation. In the process of teaching Chinese, we must abandon the traditional rigid teaching methods, interact with students, create situations 
corresponding to teaching contents, and promote the exchange and cooperation between students and teachers. Class teaching should improve the enthusiasm and initiative of students, so that the atmosphere is more intense learning. Through the crosstalk and short play, group discussions, keynote speeches and other situations to let students to learn from each other, competition, cooperation and solidarity.

(6) Situation creation accord with the students' knowledge standard and age characteristics. The stability and persistence of students' attention are closely related to age, and there is a certain relationship between knowledge level and comprehension ability. Therefore, when teachers design situation problems, it is necessary to have a certain degree of difficulty, but also meet the depth of student research. Under the premise of students' understanding the knowledge, combine the problem solving and Chinese concepts, motivate students' interests in learning, take the initiative to adapt to the situation, so as to improve the classroom teaching effect.

(7) Focus on students' exploration and potential. In the use of situational teaching, we should focus on the students' creativity and the potential, and constantly expand the curiosity, the development of critical consciousness and exploration ability. Question is what students are arguing about and we need to develop students' independent thinking ability, adhere to their own views and the courage to argue. Teachers should correctly guide students to ensure the discussion of the text as the center, develop students' critical consciousness and inquiry ability, and gradually perfect their personality.

\section{Conclusion}

According to the scene description in the text, the Chinese teacher create a series of distinctive images, with vivid literary language and artistic appeal of music, reappear the description scene of the text, and students seem to be in the meantime, for the cultivation of students' emotions, the development of imagination and the development of intellectual and other aspects with a positive effect [9]. The use of situational teaching in Chinese, has the superiority that other teaching methods can not match: create "immersive" scene for students, for students' personality and spiritual inspiration which has a very important role; use situation as a guide and learn in the simulated context, so that students can understand the article more in-depth; combine knowledge and fun as a whole, diverse forms in the class, and fully mobilize the enthusiasm of students.

\section{References}

[1] X. Li, "The application of situational teaching method in Chinese teaching," Journal of Educational Institute of Jilin Province, vol. 30, no. 1, pp. 95-96, 2014.

[2] Y. B. Ou, "On situational teaching method and its theoretical basis," Economic management, vol. 13, no. 9, pp. 52-52, 2016.

[3] X. N. Zhao, "Research and application of Situational Teaching," Journal of Hubei Correspondence University, vol. 21, no. 4, pp. 100-101, 2014.

[4] H. J. Wang, "Beautiful music, Let the Chinese classroom more vivid," New curriculum learning, vol. 10, no. 3, pp. 37-38, 2015.

[5] H. Chen, "Create life situation, improve the efficiency of Chinese Teaching," Read and Write Periodical, vol. 11, no. 9, pp. 91-91, 2014.

[6] W. L. Liu, "On the application of situational teaching method in Chinese teaching in junior middle school," Learning Weekly, vol. 10, no. 36, pp. 144-145, 2016.

[7] X. Li, "study on the situational teaching strategy in primary school Chinese Teaching," Read and write, vol. 12, no. 7, pp. 188-188, 2016. 
[8] H. B. Li, "Application of situational teaching method in College Chinese teaching in science and Engineering Colleges," Data of Culture and Education, vol. 36, no. 28, pp. 197-198, 2009.

[9] X. H. Zhu, "Application of situational teaching method in Chinese Teaching," Occupation, vol. 20, no. 2, pp. 95-96, 2013. 